\title{
Usos de la ironía en la narrativa de Washington Delgado
}

\author{
Jorge Valenzuela GarcÉs \\ Universidad Nacional Mayor de San Marcos \\ jorgevalenzuela3@hotmail.com
}

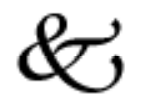

Resumen

En este artículo analizaremos el cuento "La muerte del Dr. Octavio Aguilar" de Washington Delgado, notable poeta de la generación del 50. Nos proponemos analizar la forma en que el autor emplea algunas modalidades de la ironía, como la de situación o de postura, para la descripción de la experiencia de la muerte, hecho central en el relato. La hipótesis es que en este cuento la muerte se presenta como el estado que explica las condiciones existenciales del personaje central y como una presencia que es sentida desde la infancia y que por lo tanto puede ser descrita.

Palabras claves: Washington Delgado, ironía de postura, ironía de situación, "La muerte del Dr. Octavio Aguilar", cuento peruano.

\begin{abstract}
The way in which Washington Delgado, outstanding oeta of the 50's generation, uses a modality of irony for de description of the experience of death in his short story "The death of Dr. Octavio Aguilar" is analysed in this article. In the story, death es shown as th estate that explains the existential condition of the main carácter and as a presence felt from childhood, thus fit to be described.
\end{abstract}

Keywords: Washington Delgado, Irony, "The death of Dr. Octavio Aguilar”, Peruvian Short Story. 


\section{Introducción}

La obra narrativa de Washington Delgado está constituida por un racimo de cuentos publicados de manera muy esporádica a lo largo de los años. Se sabe que hacia el final de su vida el autor tenía el proyecto de escribir algunos más, los que conformarían un libro para el que ya tenía título: Mi tía Carolina y otros parientes ${ }^{1}$.

Comparada con su obra poética, el ejercicio de la prosa es más bien, como dijimos, en el autor de Días del corazón, episódico, pero no por ello carente de calidad. La prueba de su talento narrativo nos la da el hecho de que el relato "La muerte del Dr. Octavio Aguilar" le permitió ganar, en 1979, el más importante concurso de cuento en el Perú, el Premio Copé.

Cultor de una prosa vinculada con universos íntimos, la narrativa de Delgado transita fundamentalmente por dos caminos. El primero, se orienta por el recuerdo de experiencias referidas al ámbito familiar tratados con sentida evocación no exenta de humor. El espacio referido es casi siempre el de la niñez. El recuerdo normalmente sirve para recuperar una anécdota en la que un pariente del narrador es el protagonista. El hecho narrado sirve para que aquel pueda ir recuperando la verdadera identidad de sus allegados. Allí están los excelentes cuentos "Los relojes de la tía Carolina" o "Mi primo Luis y su prima Luisa”. El segundo camino discurre por la exploración en la interioridad de personajes sumidos en situaciones límite. En esos cuentos se describe a sujetos en proceso de desintegración en un momento de sus vidas en el que la presión del entorno los ha conducido a la renuncia, a la negación, a su propia disolución.

Con respecto a esta última vía cultivada por Delgado, habría que anotar que el autor desarrolla una estrategia vinculada con los modos de la narración fantástica cuyo despliegue los convierte, por sus resultados, en una cala singular en nuestra tradición cuentística. Es el caso del cuento "La muerte del Dr. Octavio Aguilar" cuyo despliegue busca ilustrar una condición imposible en cualquier sujeto: la de estar muerto y sin embargo ser consciente plenamente de esa condición.

Ricardo González Vigil escribió en el prólogo a la antología que re-

1 Ver la entrevista "Washington Delgado: Yo me siento libre cuando escribo" que le realiza Ann Mary Linch Solís. En ella Delgado habla de su proyecto narrativo. Ver las referencias bibliográficas. 
cogió los cuentos ganadores del Premio Copé de 1979, que el cuento de Delgado tenía ciertas influencias de Kafka y del Cortázar de Bestiario y que presentaba "admirablemente lo insólito dentro de una atmósfera cotidiana, deliberadamente informativa y apática” (1981:18). Agregaba el crítico que no se conocía "ningún cuento en las letras peruanas comparable con el afán de tornar natural lo extraño".

Por su lado, y con respecto al mismo cuento, Abelardo Oquendo (1981:119) sostuvo que Ricardo González Vigil se equivocaba en su juicio, pues el tratamiento de la anécdota no tornaba natural lo extraño sino exactamente lo contrario, es decir, tornaba extraño lo natural y que precisamente por ello el cuento "confería interés a lo que de otro modo no lo tendría” (1981: 119). Sea como fuere, el cuento posee más valores que los reconocidos por estos dos críticos.

En este artículo lo que nos proponemos es, fundamentalmente, observar cómo la estrategia general del cuento apunta, precisamente, a tornar extraño lo natural gracias al empleo de la ironía y a observar las consecuencias que este manejo tiene en el nivel semántico de la narración.

\section{La muerte sentida}

El cuento se organiza sobre un acontecimiento central: la singular muerte del personaje protagónico. La historia articulada sobre este acontecimiento se despliega estratégicamente en profundidad, es decir, los acontecimientos transcurren en unas pocas horas, los espacios referidos son escasos y concentran la acción, y el análisis de la conflictiva subjetividad del personaje ocupa el centro de la narración.

Para comenzar habría que decir que la muerte es percibida por el protagonista, Octavio Aguilar, como un acontecimiento, es decir, es experimentada a través de sensaciones que el personaje puede reconocer e identificar a través de su propio cuerpo. En el cuento la experiencia de la muerte es corporal y solo se accede a ella porque se posee un cuerpo. Además, la muerte es un acontecimiento recurrente, cuya repetición se experimenta, inicialmente, como un sufrimiento del que se desea escapar como si se tratase de una pesadilla. 
La muerte es "sentida" y "vivida" por el personaje desde su infancia. De esta manera, la muerte es percibida desde un cuerpo que la reconoce o que la recuerda en sus manifestaciones y con la que, por estas circunstancias, mantiene cierta familiaridad. Citemos: "Viejos padecimientos olvidados volvieron a su mente: de niño se despertaba, a veces, con un tumulto en el corazón, con la sangre zumbándole en el oído, con unas desesperadas ganas de levantarse y sin poder hacerlo, sin poder hablar, ni gritar, ni respirar siquiera; eran unos apretados instantes que a él le parecían una eternidad, durante los cuales llegaba a sentir el aletazo de la locura o la muerte..." (p.147).

Bajo la premisa de que la muerte es un acontecimiento familiar al personaje, la narración incidirá en ella como si se tratase de un hecho natural. Un hecho que termina imponiéndose en el relato con todas sus consecuencias, instalando, de este modo en el relato, un conjunto de licencias cuya lógica rebasa los principios que gobiernan las leyes naturales.

Los asaltos de la muerte sufridos por Aguilar serán reseñados en el cuento y podrá saberse que durante su infancia, la muerte aparecerá y desaparecerá, será turbación que paralizará al cuerpo, asalto que ahogará y enmudecerá al personaje y que convertirá al tiempo cronológico en eternidad. En suma, un acontecimiento del que un cuerpo sufriente deseará escapar a través de los propios mecanismos que el cuerpo puede proporcionarle.

Sin embargo, cuando Aguilar se encuentra en un momento álgido de su vida (su elección como decano de una Facultad universitaria) la muerte volverá a instalarse en él precedida por la fuerte somatización de un estado de angustia. En este estado, el personaje siente a la muerte a través de una bola que oprime el pecho, aprieta su corazón y no lo deja respirar. En este estado, la opresión física lo inmoviliza y se convierte en un infausto anuncio.

Inutilizado el cuerpo, la muerte mostrará su rostro definitivo, una nueva estrategia de aproximación. Sus asaltos, que normalmente se manifestaban en el sueño, se producirán en plena vigilia. La mente de Aguilar empieza a morir o a ser conciente de su propia muerte y a querer independizarse del cuerpo que la aprisiona. Cuando esto empieza a 
suceder, su corazón ha dejado de la latir.

La muerte de Aguilar es descrita por el narrador como "un sutil desdoblamiento, como la pérdida de lo que (éste) había considerado, hasta entonces, más propiamente suyo" (1981:156). Este desdoblamiento afecta al personaje separando su universo corporal de su universo intelectual. La muerte se va instalando en Aguilar a través de la fatiga, el olvido, el alejamiento de sí mismo y por último, la indiferencia frente a cualquier estímulo o interés. Así, Aguilar va perdiendo aquello que consideraba lo más auténtico e intocable de sí mismo: su mundo interior.

Este espacio interior en el que le era posible reconocerse va oscureciéndose, clausurándose, de manera que la admiración, filiación y vínculo con el mundo y sobre todo con el lenguaje, su más preciada posesión, (no olvidemos que es un profesor de literatura especialista en poesía) deja de serle familiar.

En esta situación de reposo, Octavio Aguilar presencia lo que para él es su muerte definitiva. Es decir, se observa a sí mismo en un escenario en el que se produce el abandono de su propio cuerpo. Aguilar lo siente y percibe como "una penumbra desolada, un mar oscuro y quieto en el que, súbitamente, vio flotar su propio cuerpo sin vida...” (1981:156).

La muerte se instala en Aguilar a través de un creciente extrañamiento de sí mismo. Esta situación insoportable hace que la muerte total sea deseada por Aguilar. En la lógica del relato esto equivale a decir que Aguilar solo quiere dejar de experimentar cualquier tipo de estado de conciencia, lo que, por cierto, le resulta imposible. Desde esta contradicción o desde esta imposibilidad, el cuento ensayará una interesante estrategia discursiva cuya característica fundamental será la puesta en funcionamiento de los recursos de la ironía.

\section{La ironización general de la realidad: la vigilia de la muerte}

Definida como un tropo que consiste en decir lo contrario de lo que se quiere hacer entender a un destinatario, en la ironía, además, se produce una transferencia de sentido que implica contradicción.

El empleo de la ironía puede ser múltiple. Normalmente es un procedimiento que sirve para explotar mejor las diversas materiali- 
zaciones del humor. Vemos a la ironía funcionando en la caricatura, la parodia, la exageración y también la vemos vinculada a disciplinas de diversa índole como la religión, la política o la literatura.

La ironía produce un efecto de atenuación, es decir, hace que un acto severamente atroz (como una muerte) o crítico, como un insulto, pierdan fuerza. Está presente en la contradicción semántica, en la antífrasis, que de manera general implica una designación de las cosas utilizando palabras que significan lo contrario. Por ello como tropo, la ironía implica un desfase entre el sentido literal y el sentido figurado sólo visible cuando la enunciación nos permite reconocerla a través de mecanismos como la distorsión o la exageración

En el cuento de Washington Delgado, objeto de análisis, la ironía muestra estas estrategias, pero es, sobre todo, un instrumento con el cual se afecta y contradicen las leyes naturales y de la razón. Contradicción que, por ejemplo, la narración fantástica ha privilegiado siempre en el propósito de suspender los mecanismos de la lógica que utilizamos para situarnos en el mundo. Parecieran, también, estar presentes los modos de la ironía romántica, aquella en la se da expresión a la incapacidad de ajustar totalmente lo subjetivo a lo objetivo, y en la que los pensamientos no tienen un correlato en el mundo objetivo, en el mundo físico. Pensemos, en primer término, en la distancia existente entre los pensamientos del protagonista sobre sí mismo en su condición de vivo y su condición de muerto desde la que irónicamente se producen sus razonamientos, o en el desajuste experimentado por Aguilar con respecto a las expectativas que despierta en quienes creen en él como autoridad decanal y sus verdaderos deseos de desaparecer (morir) frente a las presiones que suponen esas expectativas.

Para el análisis del cuento que nos ocupa es pertinente mencionar que Octavio Aguilar es un intelectual cuya arma más poderosa es la razón, arma con la cual no podrá interpretar y comprender cabalmente su singular situación: el estar muerto, circunstancia desde ya irónica, pues en ella se realiza el acercamiento de extremos opuestos (la vida y la muerte) como diría Schoentjes, al referirse a la ironía de situación. Además, en el relato se cumple una condición 
fundamental en este tipo de ironía: el personaje se encuentra en "un fluir particular de los hechos en el que lo que sucede está en flagrante contradicción con lo que se considera el orden del mundo" (2003: 47). Esta flagrante contradicción, este evidente escándalo de la razón que supone el estar muerto y el estar vivo a la vez, se convierte en el eje estructural del relato.

Al inicio del cuento un fuerte estado de angustia paraliza el corazón de nuestro personaje, con lo cual, queda marcado el momento en el que figurativamente se produce su muerte física. Desde ese momento la narración, a través de la voz de su protagonista, se explaya en hacer evidente su singular e irónica situación: estar muerto y sin embargo estar plenamente consciente de ello.

La primera gran ironía se da, pues, en los términos de la contradicción. Tenemos a un muerto cuyo movimiento interior evidencia un estado de vigilia y atención. Hay, en Aguilar, por lo tanto, una autopercepción de sí mismo como un muerto. El cuento explota las virtualidades de esta situación desde el inicio y este aprovechamiento convertirá al relato en un texto de índole fantástica que gestiona la ruptura de un principio fundamental haciéndolo verosímil dentro de la lógica del relato: es posible estar muerto y ser consciente de ello.

Por otro lado, en la propuesta de Muecke sobre los modos de la ironía presentados en su libro La brújula de la ironía, el autor se refiere a un modo que es explotado en el cuento de Delgado, nos referimos a la ironía de postura.

En este modo de la ironía se narran sucesos naturales, cotidianos, prosaicos, desde una posición fuertemente subjetiva que busca, como en el cuento analizado, tornar extraño lo natural. En el cuento de Delgado, el empleo de esta estrategia será la norma general del relato. Es decir, es natural dictar una clase en la universidad, desplazarse a casa como todos los días e incluso morir, pero no lo es o resulta extraño que en medio de una clase el corazón del catedrático deje de latir y este siga pensando, que en el regreso a casa se produzca un olvido repentino y total del lugar en el que se encuentra la persona o que la muerte sea percibida en pleno estado de conciencia, ignorando las 
condiciones que impone desde su funesto dominio. Citemos: "En ese momento el corazón del Dr. Octavio Aguilar cesó de latir, el peso de su cuerpo creció hasta el infinito, su cabeza cayó sobre el pecho y cerró los párpados para hundirse en una oscuridad increíble. "Al fin", alcanzó a decirse y se dio cuenta de que estaba muerto, lo que no dejaba de ser curioso, sobre todo para él, hombre escéptico y razonador" (1981:148). O, "sin las angustias ni fatigas de la tarde, no se lavó ni acicaló antes de irse a la cama, pero se puso el pijama y solo al momento de apagar la luz, cuando estuvo acostado, pensó: ¿qué pasará mañana? (...) Cerró los ojos y, como ya estaba muerto, se durmió sin ahogos ni sobresaltos, sin temer las acometidas de la muerte" (1981:167). Este extrañamiento de lo natural es el procedimiento que se despliega a lo largo del relato y convierte a Octavio Aguilar en un exiliado de sí mismo.

La ironía tiene, también, otras manifestaciones en el cuento de Delgado. Para los efectos de la narración de los hechos, el autor ha construido a un narrador cuyo lenguaje coloquial y desenfadado apunta a desacralizar la excepcional situación en la que se encuentra el personaje protagónico. La narración de la muerte de Octavio Aguilar no se corresponde con la solemnidad que un hecho como la muerte comporta. En la narración de este suceso están ausentes el respeto, la reverencia y el dolor sentido. La forma y el tono de la narración no se hallan acordes con el carácter flébil de las circunstancias. El tono humorístico general de la narración apunta irreverentemente a lograr ese propósito. Citemos algunos ejemplos: "A partir de estos más o menos ingeniosos juegos de palabras, la voz pedante e inagotable de Zanabria continuaba taladrando la oscuridad sin vida del doctor Octavio Aguilar con unos ojos bilingües. "De nada me vale estar muerto" pensó desengañadamente el cadáver inerme” (1981:148). O “el doctor Aguilar, muerto perdido bajo el sol, las vio pasar (a las muchachas) con desorientado gesto y se dio cuenta que estaba hecho un pasmarote, parado tontamente en la avenida Arequipa, mirando a un lado y a otro" (1981:152). O, "sin decir palabra, se sentó junto a Bonamí y partieron, también ruidosamente, abandonando -seguramente para siempre- el 
lugar donde había ocurrido su muerte” (1981:151).

El mismo recurso se advierte en los accesos conscientes del propio Octavio Aguilar reproducidos por el narrador: "Estaré muerto, se dijo, pero no permitiré ningún escándalo sobre mi cadáver, tengo que llegar a mi casa" (1981:149).

La ironía más implacable, sin embargo, es aquella que se materializa en las relaciones del protagonista con el lenguaje, en su dominio del logos, del pensamiento. Es la llamada ironía de sentido. Resulta irónico que a Octavio Aguilar todo le resulte incomprensible precisamente desde un punto de vista razonable o que le sea imposible dominar sus propias palabras: "Mientras hablaba sintió lo que había sentido otra vez ese mismo día: que las palabras salían de su boca como objetos autónomos, como globos libres que, independientemente de su voluntad y de su conciencia, flotaban blandamente y a su guisa en el aire quieto" (1981:163).

\section{Conclusiones}

Concebida como un tropo cuyo objetivo cimero es destacar la inconsistencia o incongruencia de alguien o algo, la ironía y sus formas, en el cuento "La muerte del Dr. Octavio Aguilar" ponen en evidencia, precisamente, el contradictorio estado en el que se encuentra el protagonista. La ironía sirve, en este caso, al propósito de mostrar cómo alguien que está vivo se siente como un muerto; cómo alguien que desea morir, no puede conseguir su propósito; cómo alguien que quiere gobernar su mundo interior, siente que este se ha desintegrado.

La condición existencial del Dr. Octavio Aguilar sólo se explica, en el cuento, desde el ámbito de la muerte, desde las sensaciones que, irónicamente, se construyen para darnos a entender un estado imposible. Esa es la gran ironía que nos presenta el relato al utilizar a la muerte y su significado para la descripción de un estado de absoluta saturación vital, de presión social.

En este cuento predomina la ironía de situación pues el personaje no ignora lo que sucede, como en la ironía dramática, sino que vive, junto con los lectores, una serie de eventos que van construyendo un 
fluir particular en el que lo que sucede está en flagrante contradicción con lo que se considera el orden del mundo, como sostiene Schoentjes. Es situacional, también, porque el personaje va viviendo los acontecimientos de una forma contraria a la esperada.

Al leer el cuento, los lectores advertimos y resolvemos las contradicciones que nos plantea la situación por la que atraviesa el personaje principal convertido en ironista de su propio destino a través de la voz del narrador. Advertimos el choque irónico, la contradicción y hasta el absurdo de los pensamientos y acciones, por desproporcionados, por hiperbólicos, generados por el protagonista. De este modo nuestro papel es activo y complementario y nos exime del papel de víctima que en otros casos reclama el ejercicio de la ironía.

El personaje de Octavio Aguilar se construye, en el cuento, por oposición, por una dinámica contradictoria en la que el eje vida/muerte es estructural. Fuera de su cuerpo, arrojado de sí mismo, despojado de su memoria y de su propio lenguaje, extraño en un mundo que no reconoce, Octavio Aguilar es un muerto en vida que condensa la condición existencial del hombre contemporáneo, aquella que lo imagina como un exiliado de su propia interioridad, como un marginal a un centro productor de sentido.

\section{Referencias bibliográficas}

DELGADO, Washington (1981): "La muerte del doctor Octavio Aguilar". En V.V. A.A. Premio Copé de Cuento 1979. Lima, Ediciones Copé; pp.143-167

GONZÁLEZ VIGIL, Ricardo (1981): "Prólogo". En V.V. A.A: Premio Copé de cuento 1979. Lima, Ediciones Copé; pp.11-20.

LYNCH SOLÍS, Ann Mary (1996): "Washington Delgado: Yo me siento libre cuando escribo". En La casa de carton, 9; pp.2-14.

MUECKE, D.C. (1969): The compass of irony. London, Metheun \& Co. OQUENDO, Abelardo (1981): "Premio Copé: Los números y las letras". En Hueso húmero, 9; pp.117-120.

SCHOENTJES, Pierre (2003): La poética de la ironía. Madrid, Cátedra. 